\title{
Misoprostol for prevention and treatment of postpartum haemorrhage: A systematic review
}

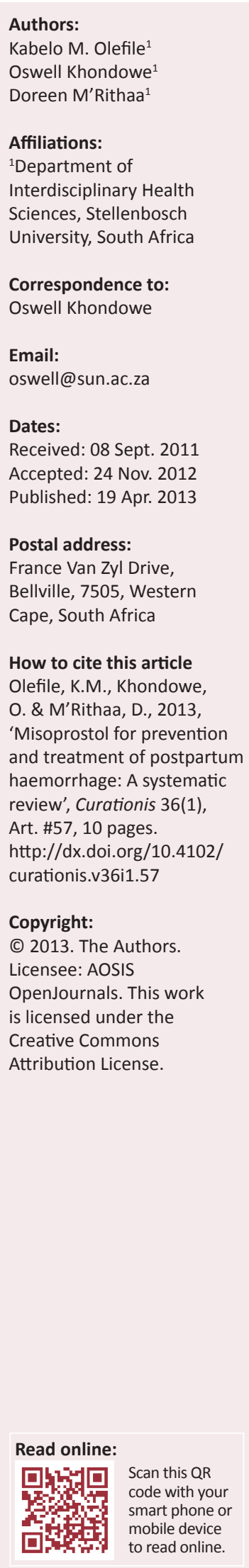

Background: Postpartum haemorrhage (PPH) is a leading cause of maternal mortality especially in the developing world. Misoprostol, a highly effective drug is highly effective in inducing uterine contractions and has been proposed as a low-cost, easy-to-use intervention for PPH.

Objective: This study assessed evidence of the effectiveness of misoprostol for the prevention and treatment of PPH.

Method: Databases searched included MEDLINE, PUBMED, CINHAL, Google Scholar, Cochrane Central Register of Controlled Trials (CENTRAL) and EMBASE. Reference lists and conference proceedings were also searched for more studies. Three studies included in the meta-analysis were limited to randomised controlled trials (RCT). Two reviewers independently screened all articles for methodological quality using a standardised instrument adapted from the Cochrane Collaboration website. Data were entered in Review Manager 5.1 software for analysis.

Results: Three trials $(n=2346)$ compared misoprostol to a placebo. Misoprostol was shown not to be effective in reducing PPH (risk ratios [RR] 0.65; 95\% confidence interval [CI] 0.40-1.06). Only one trial reported on the need for a blood transfusion (RR 0.14; 95\% CI 0.02-1.15). Shivering (RR 2.75; 95\% CI 2.26-3.34) and pyrexia (RR 5.34; 95\% CI 2.86-9.96) were significantly more common with misoprostol than with a placebo.

Conclusion: The use of misoprostol was not associated with any significant reduction in the incidence of PPH. Therefore, in order to verify the efficacious use of misoprostol in the treatment of PPH, specialised investigations of its dose and routes of administration for clinically significant effects and acceptable side effects are warranted.

\section{Introduction}

Maternal mortality continues to be one of the most serious and intractable health problems for women of reproductive age in low-income countries (Tsu \& Shane 2004:83). To reduce the maternal mortality ratio by three quarters by 2015 is the target for one of the eight Millennium Development Goals (MDGs) set by 189 countries in 2000 (Rosenfield, Maine \& Freedman 2006:1333). Postpartum haemorrhage (PPH), the leading cause of maternal deaths worldwide, has been receiving increased attention amongst medical researchers for the last few decades. The World Health Organization (WHO 2007) defines PPH as postpartum blood loss of $500 \mathrm{~mL}$ or more from the genital tract. However, in populations with a higher prevalence of anaemia, blood loss of less than $500 \mathrm{~mL}$ has been reported to have several physical consequences (McCormick et al. 2002:267).

\section{Statement of the problem}

The maternal mortality ratio in developing countries is 450 maternal deaths per 100000 live births versus nine in developed countries (WHO 2007). An estimated 358000 maternal deaths occurred worldwide in 2008 (UNICEF 2010). According to UNICEF (2010), out of 1000 maternal deaths due to severe bleeding after childbirth, 560 deaths occurred in sub-Saharan Africa and 300 in South Asia compared to five in high-income countries. According to the Millennium Development Goals (MDGs) report (2010), there was a significant reduction in maternal mortality ratios (MMRs) in developing regions. The average annual percentage decline in the global MMR was 2.3\% - short of the MDG target of 5.5\%. However, in 2008 in sub-Saharan Africa, where levels of mortality were highest, there was an estimated $1.7 \%$ annual rate of decline - slower than in any other region. According to UNICEF (2010), the maternal mortality ratio in South Africa was 410 in 100000 live births in 2008.

The Saving Mothers report (2007:12) states that obstetric haemorrhage is the third most common cause of maternal death in South Africa (SA), accounting for 491 (12.4\%) of all maternal deaths during the period from 2005 to 2007. Substandard care remained a major problem in SA, contributing 
to over $40 \%$ of deaths for every level of care. This includes failure to carry out essential steps of prescribed protocols, or serious delays in doing so, and lack of appropriate skills. According to Fawcus and Moodley (2011), it is fundamental that all levels of care are able to deal with the emergency management of $\mathrm{PPH}$ and are aware of the factors required to prevent it. This necessitates sufficient facilities, supplies and skilled staff. Major improvements in the implementation of the health system and appropriate training of doctors and midwives at all levels of care are essential if deaths from this preventable cause of maternal mortality are to be reduced.

Aetiology of postpartum haemorrhage: PPH results mainly from uterine atony. Pillitteri and Klweri (2010:677) state that correlates such as multiple gestation, hydramnios, macrosomic baby, presence of uterine myomas, operative birth, rapid birth, placenta praevia, placenta abruption, retained placenta fragments, secondary maternal illness, prolonged use of magnesium sulphate or tocolytic therapy, disseminated intravascular coagulation and high parity predispose women to uterine atony. Other aetiologies include coagulation defects, retained placenta and trauma.

\section{Description of intervention}

Weeks and Faúndes (2007) delineate misoprostol as a prostaglandin $\mathrm{E}_{1}$-analogue with uterotonic properties that can be administered orally, sublingually, vaginally and rectally. Sublingual administration of misoprostol achieves the uppermost serum peak absorption and takes the shortest time to reach the peak level in comparison with other routes of administration (Tang et al. 2002). Initially, misoprostol was introduced as treatment for peptic ulcers. Misoprostol has been used to treat a variety of obstetrical problems, including uterine atony, postpartum haemorrhage, the induction of labour and the induction of abortion (Hofmeyr et al. 2005). Ng et al. (2001) observed that misoprostol, when given postpartum, is known to cause only mild side effects (shivering and pyrexia). However, misoprostol is a sustainable drug for use in developing countries for the treatment of an assortment of obstetrical complications (Winikoff et al. 2010).

\section{How misoprostol might work}

The key management of $\mathrm{PPH}$ involves rapid recognition and diagnosis of the condition, as well as restoration of circulating blood volume with a simultaneous search for the cause. According to WHO (2000), injectable oxytocin and ergometrine have been recommended for routine use in the active management of the third stage of labour. However, the administration of an injection requires skills and sterile equipment for safe administration. Oxytocin may be inactivated if exposed to high ambient temperatures and requires cold-chain storage. WHO (2000) regard oxytocin as the gold standard for treatment of postpartum haemorrhage. Mousa and Alfirevic (2007) state that misoprostol is highly effective in inducing uterine contractions and has been proposed as a low-cost, easy-to-use alternative to oxytocin.
Oxytocin is usually the preferred drug where active management of the third stage of labour is practised (Gülmezoglu et al. 2001; Langenbach 2006). Zuberi et al. (2008) advocated for the availability of misoprostol in communitybased settings with limited access to conventional injectable uterotonics. Misoprostol has an important role to play in hospital settings and its adjunct use should continue to be explored for its potential in the quick, safe and effective controlling of postpartum bleeding, averting recourse to more invasive procedures and preventing more severe maternal morbidity (Zuberi et al. 2008). Ng et al. (2001) observed that when misoprostol is given postpartum it produces only mild side effects (shivering and pyrexia), which are dose-dependent.

\section{Significance of this research}

Although there are several interventions for prevention and treatment of $\mathrm{PPH}$, the results of most studies on use of misoprostol for PPH are contradictory. Several systematic reviews have assessed the effectiveness of misoprostol in the prevention of PPH (Gülmezoglu et al. 2011; Hofmeyer et al. 2005; Langenbach 2006; Mousa \& Alfirevic 2007). These reviewers looked at the possibility that misoprostol can be used as first-line of therapy in the absence of injectable uterotonics. However, the results of some of the aforementioned reviews do show the significance of misoprostol in the prevention and treatment of PPH. Furthermore, these reviews included studies that compared misoprostol to a placebo in addition to standard uterotonics used in routine practice. Thus, the question arises whether the real effectiveness of misoprostol used in the third stage of labour is affected by its combined use with additional uterotonics. A systematic review is therefore needed to collate and assess the effectiveness of misoprostol alone (i.e. without other uterotonics) compared to a placebo for the prevention and treatment of $\mathrm{PPH}$, particularly in cases where other uterotonic agents are not feasible.

\section{Objectives}

The objective of this systematic review was to assess evidence on the effectiveness of misoprostol compared to a placebo for the prevention and treatment of $\mathrm{PPH}$.

Specific objectives: The specific objectives were to determine the effectiveness of misoprostol in preventing and treating blood loss of $\geq 500 \mathrm{~mL}$ and to investigate maternal mortality and severe morbidities associated with the use of misoprostol compared to a placebo for the prevention of $\mathrm{PPH}$.

\section{Research methods and design Criteria for considering studies for this review}

Types of studies: Randomised controlled trials (RCT) that assessed the effectiveness of misoprostol compared to a placebo in the prevention and treatment of $\mathrm{PPH}$ during vaginal delivery were included in this review.

Types of participants: Studies that included women in labour with anticipated vaginal deliveries, with no history 
of postpartum haemorrhage, at low risk of PPH and with singleton pregnancies were considered for inclusion. Studies that included women with Caesarean section and women with anaemia were excluded as such participants are considered to be high-risk pregnancies and vulnerable to $\mathrm{PPH}$.

Types of interventions: Interventions considered for this review were misoprostol versus a placebo, or non-treatment, for the prevention and treatment of PPH up to the third stage of labour. All studies, irrespective of dose or route (oral, sublingual or rectal) of misoprostol administration were considered for this review. Studies that compared misoprostol to a placebo in addition to other uterotonics were excluded.

\section{Types of outcomes measured}

\section{Primary outcomes}

Outcomes of interest in trials:

- Blood loss of $500 \mathrm{~mL}$

- Maternal mortality

\section{Secondary outcomes}

- Severe morbidity (hysterectomy and/or surgery, need for blood transfusion and manual removal of placenta).

- Pyrexia (temperature of $\geq 38^{\circ} \mathrm{C}$ ) and severe side effects (vomiting and shivering).

- Need for additional use of uterotonics.

For the purpose of this review, maternal morbidity was defined as the need for a blood transfusion, manual removal of the placenta, hysterectomy and major surgery, and pyrexia was defined as a temperature equal or greater than $38^{\circ} \mathrm{C}$.

\section{Electronic search}

A comprehensive search for relevant studies was conducted on the following databases: MEDLINE (Medical Literature Analysis and Retrieval System Online), PUBMED, CINHAL (Cumulative Index of Nursing and Allied Health), Google Scholar, Cochrane Central Register of Controlled Trials (CENTRAL) and EMBASE. Subsequent MeSH (Medical Subject Headings) terms used were misoprostol, ergot preparations, prevention, postpartum haemorrhage and randomised controlled trials. The search strategy used was misoprostol or cytotec or placebo, and RCT or random or controlled trials, and prevention or treatment, and postpartum haemorrhage or PPH. The search was conducted irrespective of geographical region of the study.

\section{Searching other sources}

A list of hand-searched (pearling) journals, textbooks and conference proceedings were examined for more studies. WHO Drug Administration Guidelines were also considered. Professor Hofmeyr, a specialist in obstetrics, gynaecology and midwifery, was consulted for input and appraisal of the main objective of this review.

\section{Data collection and analysis}

\section{Selection of studies}

The search yielded 339 articles. After careful reading of the titles, 294 articles were rejected. The abstracts of the remaining 45 articles were independently read by two reviewers, Kabelo Monicah Olefile (KMO) and Oswell Khondowe (OK). Thirtysix articles were excluded as they did not meet the inclusion criteria. The reasons for exclusion were that articles were reviews, editorials, reporting on outcomes not of interest, misoprostol being administered for other obstetrical uses and misoprostol being compared to other uterotonic drugs. The reviewers independently read the remaining full-text nine articles. This procedure led to the further exclusion of six articles based on the reasoning that misoprostol was compared to a placebo in addition to other uterotonics. This study therefore included three articles. See Figure 1 for the selection of articles.

\section{Data extraction and management}

Reviewers independently extracted data from the studies by using a standardised data extraction form that was adapted from the Cochrane Collaboration website. It was adjusted and refined for the purpose of this review. The refined version was piloted and used in the research process by Kabelo Monicah Olefile (KMO) and Oswell Khondowe (OK). Data were entered into Review Manager 5.1 (RevMan 5.1) for analysis.

\section{Assessment of risk of bias in included studies}

It is important to systematically complete a critical appraisal of all the studies in a review to prevent flaws, even if there is no variability in either the validity or results of the included studies (Higgins \& Green 2006). The validity of each study

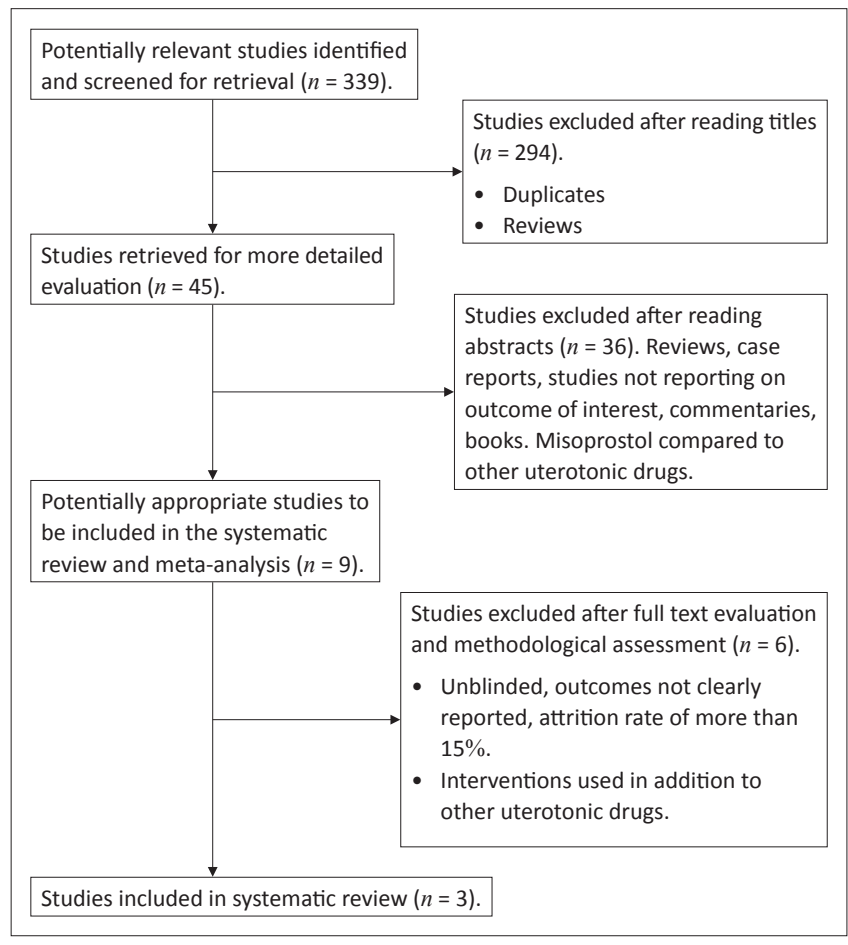

FIGURE 1: Flow diagram of electronic search. 
was assessed using the criteria outlined in the Cochrane Collaboration 'risk of bias' quality assessment tool. To determine the selection bias and performance bias, quality scores for allocation concealment and blinding were classified as follows: (1) low risk if a method such as consecutively numbered, sealed, opaque envelopes were used, (2) unclear if the concealment method was not described or (3) high risk if an open list of random records, case record numbers, dates of birth or days of the week were used. Allocation concealment was considered adequate in all three included studies as sealed envelopes, opaque containers or identical numbered boxes containing identical trial medications were used. In one trial, traditional birth attendants carried out the trial, the allocation of interventions was not stated and relevant data for analysis were not recorded (Prata et al. 2005).

For attrition bias due to loss to follow-up, protocol deviations, withdrawals and dropouts, completeness was assessed by looking at the percentage of participants lost. Studies were considered to be unbiased if the loss of participants was less than $15 \%$. In the trial described by Derman et al. (2006), a total of four women (attrition rate of $0.25 \%$ ) did not receive the trial treatments, but were included for analysis. In the other two trials included in this study (Hoj et al. 2005; Suberk et al. 1999) there was no loss of participants.

The assessment of PPH has a potential bias if the researchers making the assessments are not blinded to the intervention. In this review, double blinding was confirmed in three included studies, but in Prata et al. (2005) blinding was not preformed. The three trials clearly described the methods of blood measurement used in both intervention groups. However, errors are likely to be distributed equally between the two study groups and are unlikely to have introduced any systematic bias that could have affected the significance of the study results. The article highlighted in grey in Table 1 was excluded after methodological assessment.

\section{Measures of treatment effect}

Summarised results were presented using risk ratios (RR) with a $95 \%$ confidence interval $(\mathrm{CI})$ as the measurement of effect size for binary outcomes. For continuous data (mean blood loss) weighted mean differences were not calculated, as outcomes were not measured in the same way between trials. Random effect meta-analysis (the Mantel-Haenszel method) was used, as the trials were heterogeneous. Statistical analysis was carried out using Review Manager 5.1 (RevMan 5.1).

\section{Dealing with missing data}

Reviewers proposed to contact the original authors in cases where data were missing. However, this was not necessary, as all required data were obtainable in the included articles.

\section{Assessment of heterogeneity}

A test of heterogeneity between trials was applied by using $I^{2}$. If the $I^{2}$ was between 0 and 30\% it was interpreted as mild heterogeneity. If the $I^{2}$ was between $30 \%$ and $60 \%$ it represented moderate heterogeneity, 50\% - 90\% represented substantial heterogeneity and $75 \%-100 \%$ was considerable heterogeneity. The Chi-square test was used for the power of the studies and a $p$-value of $\leq 0.05$ was used to detect significant difference amongst studies. A random-effects meta-analysis (the Mantel-Haenszel method) was used.

\section{Assessment of reporting bias}

All three trials were included for meta-analysis and were investigated for reporting bias. Reporting bias was not identified in any of the included studies. Funnel plots parallel to meta-analysis of the primary outcomes were used in assessing publication bias.

\section{Data synthesis}

All outcomes in this review were presented as binary data. Meta-analysis was performed using RevMan 5.1 software. Random-effects meta-analysis (the Mantel-Haenszel method) was used to calculate the pooled estimate. A 95\% confidence interval was calculated for each effect size estimate. Heterogeneity was measured with the $I^{2}$ test and the Chisquare test with a $p$-value of less than 0.05 to indicate a significant difference amongst studies. Forest plots were used to reveal the effect of interventions. Sub-group analysis was intended to further explore heterogeneity.

\section{Sub-group analysis and investigation of heterogeneity}

Sub-group analysis was a priori based on the dose administered and the route of administration. However, sub-grouping was being carried out on the route of administration. All included trials used a dose of $600 \mu \mathrm{g}$. Two trials, Derman et al. (2006) and Suberk et al. (1999), administered misoprostol orally and in Hoj et al. (2005) misoprostol was administered sublingually.

Table 2 shows the results of studies sub-grouped according to route of administration (orally and sublingually). There was

TABLE 1: Assessment of methodological quality: Risk of bias.

\begin{tabular}{|c|c|c|c|c|c|c|c|}
\hline Study & Sequence allocation & Allocation concealment & Blinding & $\begin{array}{l}\text { Incomplete outcome } \\
\text { data }\end{array}$ & Selective outcome reporting & $\begin{array}{l}\text { Potential } \\
\text { threats }\end{array}$ & $\begin{array}{l}\text { Attrition } \\
\text { rate (\%) }\end{array}$ \\
\hline Derman 2006 & LR-Computer generated & LR-Sealed envelopes & LR-Double blinding & LR-No data missing & LR-All outcomes reported & $U$ & 0.25 \\
\hline Hoj 2005 & HR-Random list of numbers & LR-Opaque envelopes & LR-Double blinding & LR-No data missing & LR-All outcomes reported & $U$ & 0.0 \\
\hline Prata 2005 & HR-Not described & HR-Not described & HR-Not blinded & $\begin{array}{l}\text { HR-Some outcomes } \\
\text { not reported }\end{array}$ & $\begin{array}{l}\text { HR-Some outcomes } \\
\text { not reported }\end{array}$ & $U$ & 17.5 \\
\hline Surbek 1999 & $\begin{array}{l}\text { LR-Random number } \\
\text { generated tables }\end{array}$ & $\begin{array}{l}\text { LR-Identical gelatine capsules, } \\
\text { opaque sealed envelopes }\end{array}$ & LR-Double blinding & LR-No data missing & LR-All outcomes reported & $U$ & 0.0 \\
\hline
\end{tabular}

$L R$, low risk; $H R$, high risk; $U$, unclear. 
TABLE 2: Subgroup analysis on route of administration.

\begin{tabular}{lccccccc}
\hline Outcomes & \multicolumn{3}{c}{ Orally } & & \multicolumn{3}{c}{ Sublingually } \\
\cline { 2 - 4 } \cline { 7 - 9 } & Combined RR & $\mathbf{9 5 \%}$ & $\mathbf{C l}$ & & Combined RR & $\mathbf{9 5 \%}$ & $\mathrm{Cl}$ \\
\hline $\begin{array}{l}\text { Incidence of PPH } \\
\text { (blood loss } \geq 500 \mathrm{~mL} \text { ) }\end{array}$ & 0.52 & 0.38 & 0.72 & & 0.89 & 0.76 & 1.04 \\
Pyrexia & 3.76 & 1.81 & 7.79 & & 7.11 & 3.85 & 13.12 \\
Shivering & 2.98 & 2.53 & 3.51 & & 2.43 & 1.96 & 3.01 \\
\hline
\end{tabular}

$\mathrm{RR}$, risk ratios; $\mathrm{Cl}$, confidence interval.

Sublingually, 1 study; orally, 2 studies.

no evidence of heterogeneity amongst studies. The results of all the studies were combined for meta-analysis.

\section{Sensitivity analysis}

It was pre-specified that a sensitivity analysis would be performed on the quality of the included studies, excluding trials where allocation concealment is inadequate.

\section{Reliability and validity}

Reviewers performed the assessment of the studies independently, using a standardised data extraction form. Both reviewers are trained in research methodology and OK has published systematic reviews previously.

\section{Results}

\section{Results of the search}

A search of databases and hand-searching of other literature sources yielded 339 unique citations. One reviewer (KMO) examined the titles and abstracts and identified 45 reports as potentially relevant. These were then independently screened by $\mathrm{KMO}$ and $\mathrm{OK}$. Four studies were assessed for methodological quality and one study was then excluded. Three studies were included for meta-analysis of this review.

\section{Description of studies}

See Table 3 for the characteristics of the included studies.

Included studies: Three studies with a total of 2346 participants were included. The important characteristics of the included studies are summarised in Table 3. The trials compared the effectiveness of misoprostol to a placebo for the management of the third stage of labour in pregnant women with vaginal delivery. All trials used $600 \mu \mathrm{g}$ misoprostol tablets. Two trials, Derman et al. (2006) and Suberk et al. (1999), administered misoprostol orally and in the Hoj et al. (2005) trial misoprostol was administered sublingually. The average age for participants was 23.3 years amongst all included trials. The trials were conducted in three different countries: Derman et al. (2006) in India, Hoj et al. (2005) in Guinea Bissau and Suberk et al. (1999) in Switzerland. Treatment interventions were given immediately after the delivery of the baby. Not all of the trials measured all outcomes identified for this review, but the main outcomes were presented.

Excluded studies: Thirty-six out of 45 reports were retrieved for further assessment and were excluded after reading the abstracts. Nine studies appeared to be eligible for inclusion in this review. However, six trials were excluded after fulltext examination. In one trial the methodological quality was poor, the unblinded outcomes were not clearly reported, there was an attrition rate of more than $15 \%$ and there was no randomisation. Five trials were excluded because misoprostol was compared to a placebo in addition to other uterotonics. One trial, Prata et al. (2005), was then excluded after the assessment of risk of bias.

\section{Risk of bias in included studies}

The two reviewers (KMO \& OK) assessed all of the included trials for risk of bias and were blinded to each other's assessments. Disagreements were resolved through discussions. Domains from the Cochrane Collaboration risk of bias tool were assessed for each trial. Risk of bias is detailed for each trial in the the 'risk of bias summary' (see Figure 2). In addition, an overall assessment of risk of bias can be viewed in Figure 3.

\section{Allocation (selection bias)}

The way in which comparison groups are assembled is an important factor that may lead to selection bias if not applied accordingly. Random sequence generation was rated as low risk if every participant had an equal chance of being selected for either condition or if the researchers were unable to predict the treatment group the participant was assigned to. The use of date of birth, date of admission and date of the week, or alternation resulted in labeling a study as high risk of bias. Allocation concealment was assigned to be low risk if the methods to conceal allocation, such as central

TABLE 3: Characteristics of included studies.

\begin{tabular}{|c|c|c|c|c|c|}
\hline Author & Methods & Design & Participants & Interventions & Outcomes \\
\hline Derman 2006 & $\begin{array}{l}\text { - Randomisation } \\
\text { and concealment } \\
\text { by computer } \\
\text { generated list with } \\
\text { a random block size } \\
\text { - Sealed envelopes } \\
\text { - Double blinding }\end{array}$ & $\begin{array}{l}\text { - Randomised } \\
\text { controlled trial }\end{array}$ & $\begin{array}{l}\text { - } 1620 \text { pregnant } \\
\text { with anticipated, } \\
\text { uncomplicated } \\
\text { spontaneous } \\
\text { vaginal delivery }\end{array}$ & $\begin{array}{l}\text { - } 600 \mu \mathrm{g} \text { oral misoprostol } \\
\text { versus identical placebo }\end{array}$ & $\begin{array}{l}\text { - Primary outcome: the incidence of acute postpartum } \\
\text { haemorrhage (blood loss } \geq 500 \mathrm{~mL} \text { ). } \\
\text { - Secondary outcomes: severe postpartum haemorrhage } \\
\text { (blood loss } \geq 1000 \mathrm{~mL} \text { within } 2 \text { hours of delivery) and mean } \\
\text { blood loss, need for transfer to a higher level facility, use of } \\
\text { additional open-label uterotonic agents, blood transfusion, } \\
\text { surgical intervention, maternal death, and drug-related } \\
\text { maternal and neonatal side-effects }\end{array}$ \\
\hline Hoj 2005 & $\begin{array}{l}\text { - Randomisation by } \\
\text { opaque envelopes } \\
\text { were consecutively } \\
\text { numbered }\end{array}$ & $\begin{array}{l}\text { - Randomised } \\
\text { double blinding } \\
\text { - Placebo } \\
\text { controlled trial }\end{array}$ & $\begin{array}{l}\text { - } 661 \text { women } \\
\text { undergoing } \\
\text { vaginal delivery }\end{array}$ & $\begin{array}{l}\text { - Misoprostol } 600 \mu \mathrm{g} \\
\text { or identical placebo } \\
\text { administered sublingually } \\
\text { immediately after delivery }\end{array}$ & $\begin{array}{l}\text { - Incidence of PPH (blood loss of } \geq 500 \mathrm{~mL} \text { ) } \\
\text { - Decrease in haemoglobin concentration after delivery }\end{array}$ \\
\hline Surbek 1999 & $\begin{array}{l}\text { - Random allocation } \\
\text { with number- } \\
\text { generated tables }\end{array}$ & $\begin{array}{l}\text { Randomised } \\
\text { double masked } \\
\text { placebo- } \\
\text { controlled trial }\end{array}$ & $\begin{array}{l}\text { - } 65 \text { women with } \\
\text { anticipated } \\
\text { vaginal deliveries }\end{array}$ & $\begin{array}{l}\text { - Oral dose of misoprostol } \\
(600 \mu \mathrm{g}) \text { versus identical } \\
\text { placebo immediately after } \\
\text { cord clamping }\end{array}$ & $\begin{array}{l}\text { - Primary outcome: incidence of PPH (blood loss } \geq 500 \mathrm{~mL} \text { ) } \\
\text { and by antepartum and postpartum hematocrit values } \\
\text { - Secondary outcomes: side effects, additional use of } \\
\text { oxytocics }\end{array}$ \\
\hline
\end{tabular}


randomisation, serially numbered, opaque, sealed envelopes and other descriptions with convincing concealment, were used. Concealment of allocation was considered high risk if alteration methods were used and unclear if authors did not adequately mention the concealment.

\section{Blinding (performance bias and detection bias)}

The blinding of outcome assessors to the intervention allocation reduces detection bias. Blinding of those receiving and providing care is useful in protecting against performance bias. Blinding was assigned to be low risk if both participants and personnel were unaware of the interventions they were allocated to. The trial was assigned to be at high risk of bias if participants, personnel and outcome assessors were not blinded to the intervention group. Blinding was considered to be unclear if participants, personnel and outcome assessors were not mentioned as being blinded to the interventions.

\section{Incomplete outcome data (attrition bias)}

Loss to follow-up was coded in each outcome as follows:

- Low risk: if attrition rate was less than $15 \%$ and if reasons for loss to follow-up were similar in both treatment arms.

- High risk: if more than $15 \%$ of patients were lost to followup or reasons for loss to follow-up were not mentioned.

- Unclear: if loss to follow-up was not reported.

The proportion of participants whose outcomes were analysed was recorded in this review.

\section{Selective reporting (reporting bias)}

Selective reporting is important in areas where multiple outcome measures are used (Gotzsche 1989). Specification of predefined outcomes and analysis in the trials was considered as indicators of validity. Obtaining missing data from original investigators can be used to minimize selective reporting, but it was not necessary for this trial. The criterion below was used to measure reporting bias in the trials:

- Low risk - reports of the study were free of suggestion of selective reporting.

- High risk - reports of the study suggested selective outcome reporting.

- Unclear - if analysis was by intention to treat.

\section{Other potential sources of bias}

All of the studies had insufficient information to assess whether other important risks of bias existed. Information on potential financial conflicts of interest was considered as a possible source of additional bias. The criterion below was used to give each trial an overall quality rating:

- Low risk of bias - all criteria met.

- Moderate risk of bias - one or more of the criteria partly met.

- High risk of bias - one or more criteria not met.

Figure 2 presents the trials on the vertical axis in alphabetical order and the risk of bias on the horizontal axis. The risk of bias assessment was performed in four trials after which one trial was excluded due to the high risk of bias in all domains.

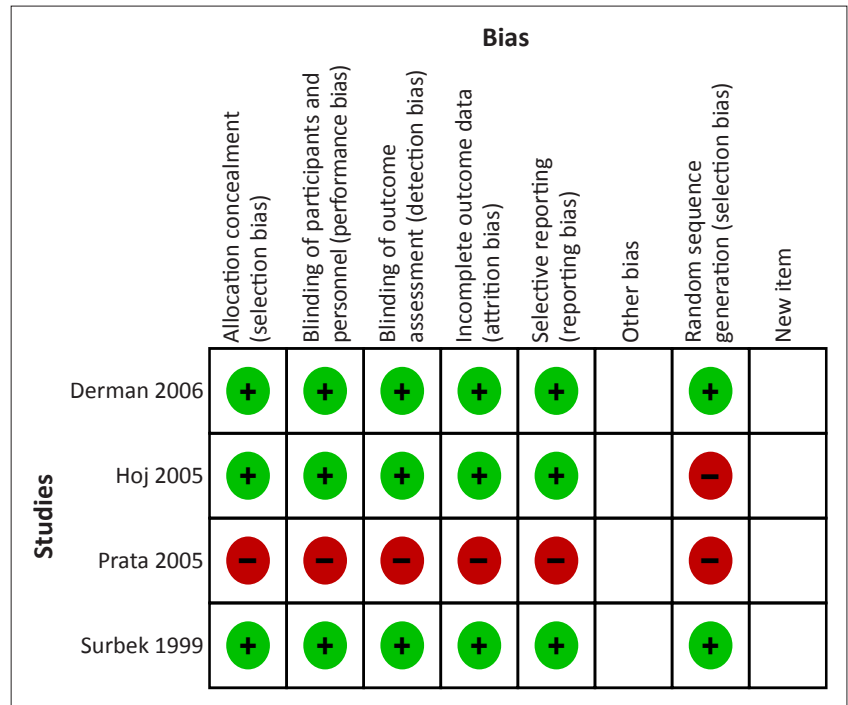

FIGURE 2: Risk of bias summary: Review authors' judgements about each risk of bias item for each included study.

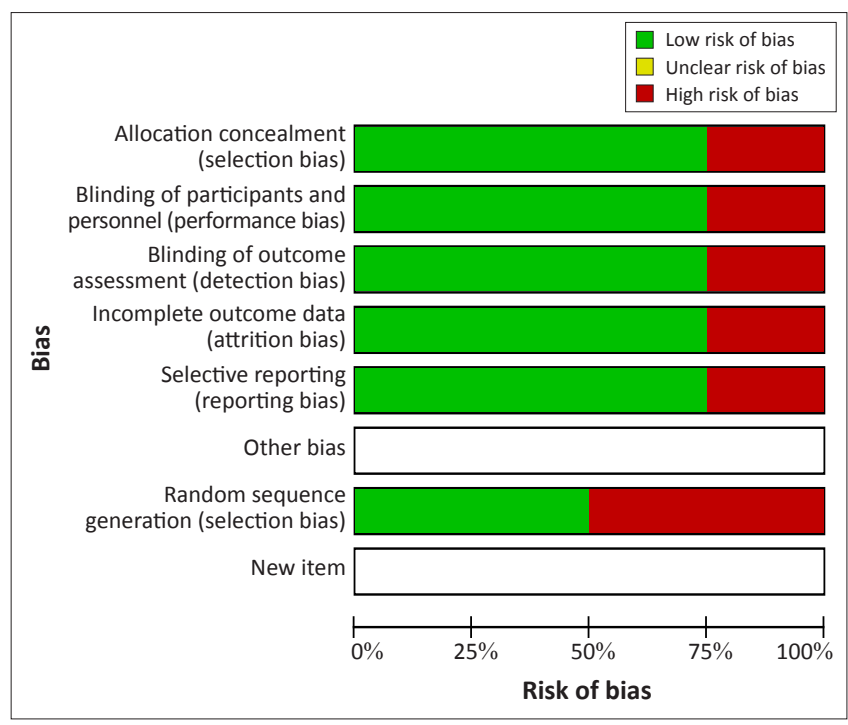

FIGURE 3: Risk of bias graph: Review authors' judgements about each risk of bias item presented as percentages across all included studies.

Figure 3 illustrates approximately 75\% confirmation of allocation concealment, blinding, incomplete data and selective reporting in the trials. Random sequence generation was addressed in about $50 \%$ of the trials. A judgement of unclear for other sources of bias, such as declaration of conflict of interest, was not reported in any of the trials.

\section{Effects of interventions Comparison: Misoprostol versus placebo}

Incidence of PPH (blood loss of $\geq 500 \mathrm{~mL}$ ): Three studies with a total of 2346 participants reported on incidence of $\mathrm{PPH}$, as shown below in Figure 4 . There was a non-significant tendency of blood loss of $\geq 500 \mathrm{~mL}$ for those who received misoprostol (RR 0.65; 95\% CI 0.40-0.06). Misoprostol does not appear to be more effective than a placebo in the treatment of PPH. There was a high level of heterogeneity amongst the studies $\left(p=0.008 ; I^{2}=79 \%\right)$. 
Need for blood transfusion: Only one trial, Derman et al. (2006), reported on the need for a blood transfusion. The study found no significant difference in the need for a blood transfusion between participants who received misoprostol and placebo (RR 0.14; 95\% CI 0.02-1.15). Heterogeneity was not applicable as only one trial reported on the need for a blood transfussion.

Hysterectomy and surgery: Only one trial (Derman et al. 2006) reported on hysterectomy or major surgery. The overall effect of misoprostol was coupled with a reduced rate of hysterectomy/surgery compared to a placebo (RR 0.12; 95\% CI 0.02-0.99; $p=0.05$ ). A test for heterogeneity was not computed as there was only one trial for this analysis.

Pyrexia: Figure 5 below illustrates the occurrence of pyrexia in two trials. Participants that were given misoprostol had a 5.34 times higher probability of experiencing pyrexia compared to those who received a placebo. We can be $95 \%$ confident that the true value of the population lies between
2.86 and 9.96. There was no evidence of a significant difference in the results of the studies included for the outcome pyrexia $\left(p=0.19 ; I^{2}=42 \%\right)$.

Shivering: Figure 6 shows binary data of three trials with 2346 participants. Participants that were given misoprostol had a 2.76 times higher probability of shivering compared to those who received a placebo. Misoprostol was not associated with a significant reduction in shivering. We can be $95 \%$ certain that the true value of the population lies between 2.26 and 3.34. Some evidence of statistical heterogeneity was detected in the studies $(p=0.21)$, but the $p$-value was insignificant.

Need for additional uterotonics: Figure 7 below shows the results of two studies. Participants in the misoprostol group showed a $54 \%$ reduction in the need for additional uterotonics compared to those who received a placebo (RR $0.44 ; 95 \%$ CI $0.21-0.95 ; p=0.04)$. The trials were heterogeneous $\left(\mathrm{Chi}^{2}=0.04 ; I^{2}=0 \% ; p=0.84\right)$ and there was no significant difference amongst all the studies as they strongly favored misoprostol with a risk ratio of less than one.

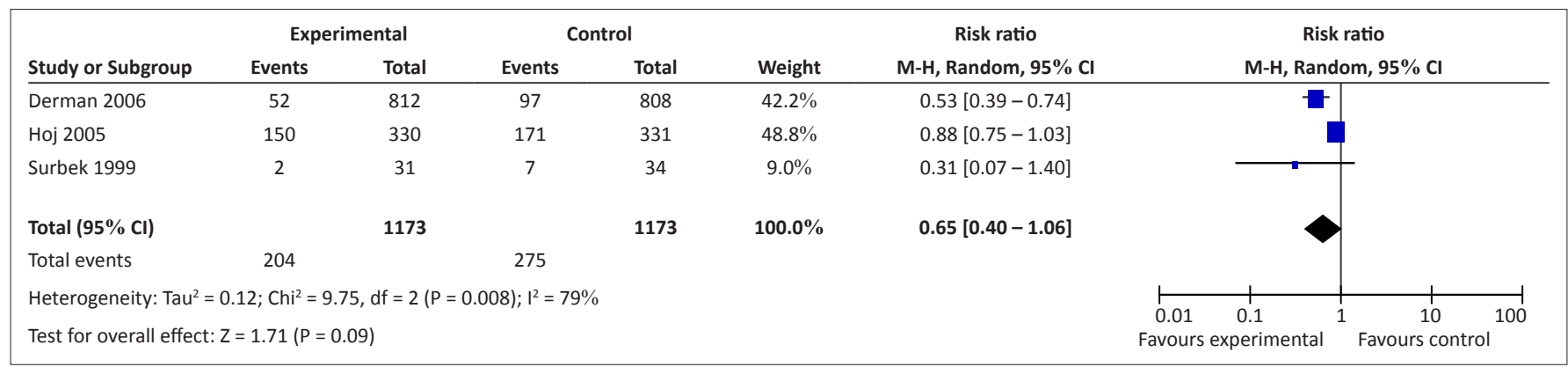

$\mathrm{Cl}$, confidence interval.

FIGURE 4: Random effect analysis of misoprostol versus a placebo in the prevention and treatment of Postpartum haemorrhage on incidence of Postpartum haemorrhage.

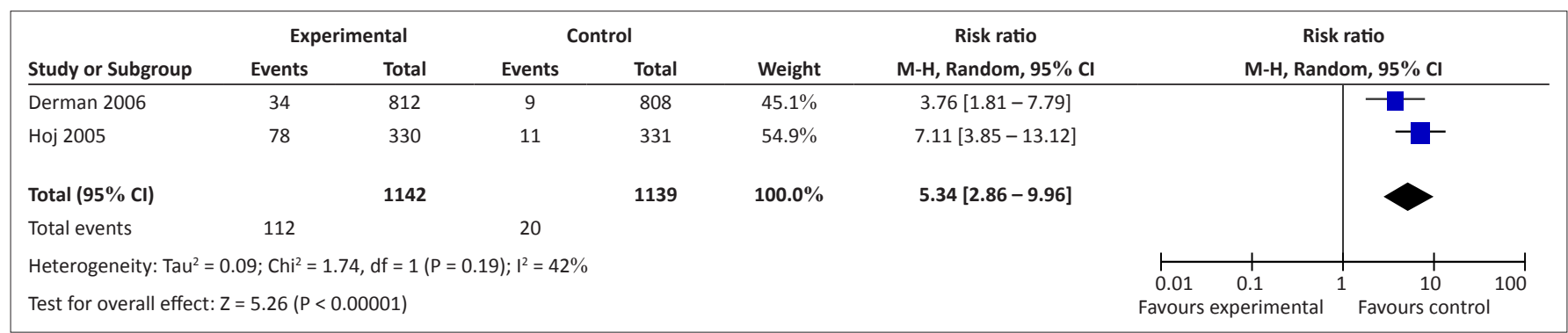

$\mathrm{Cl}$, confidence interval.

FIGURE 5: Random effect analysis of misoprostol versus a placebo in the prevention and treatment of Postpartum haemorrhage on pyrexia.

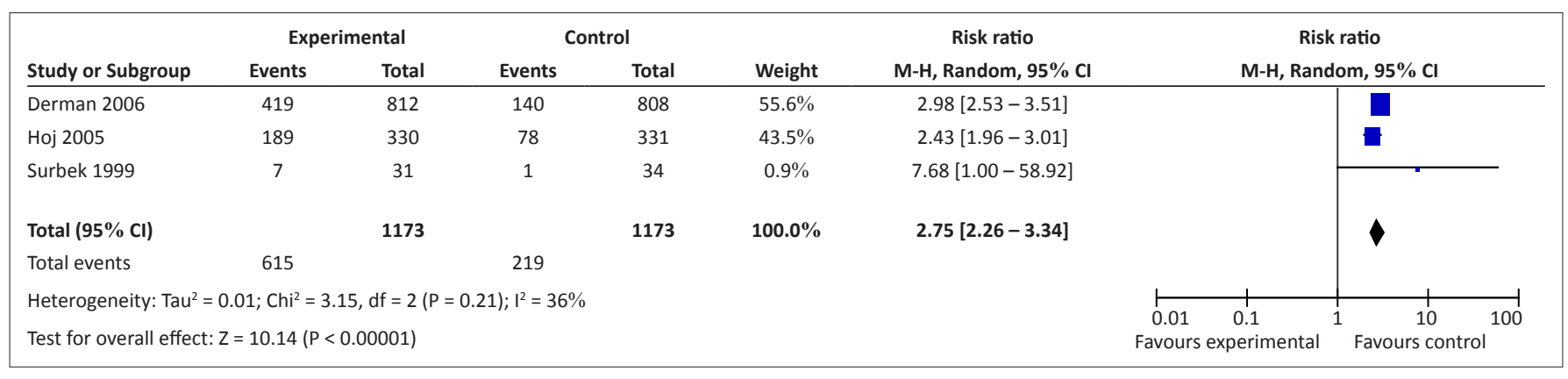

$\mathrm{Cl}$, confidence interval.

FIGURE 6: Random effect analysis of misoprostol versus placebo in the prevention and treatment of Postpartum haemorrhage on shivering. 


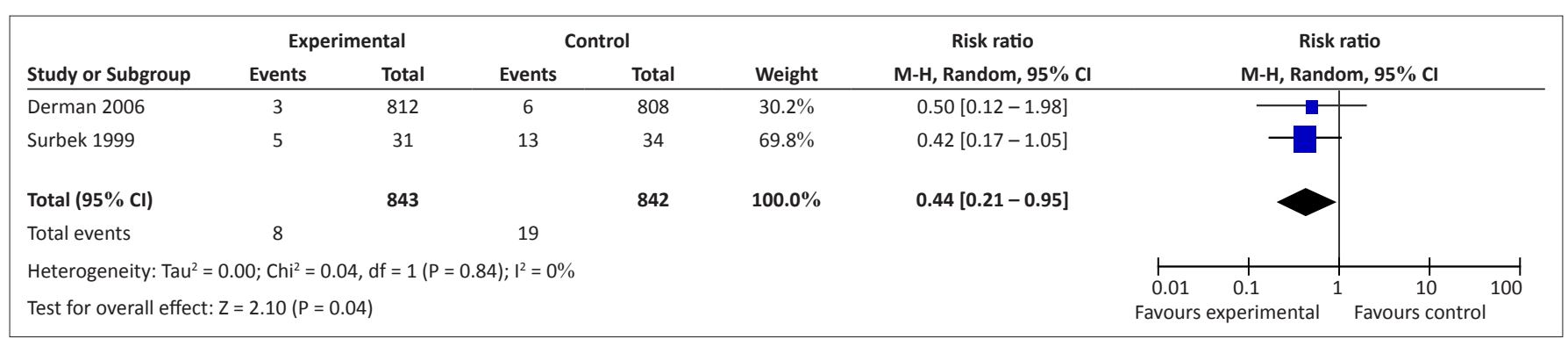

$\mathrm{Cl}$, confidence interval.

FIGURE 7: Random effect analysis of misoprostol versus a placebo in the prevention and treatment of Postpartum haemorrhage on need for additional uterotonics.

The results of the studies show that misoprostol administered either orally or sublingually does not show a significant reduction in postpartum blood loss. Side effects, pyrexia and shivering were persistent in the misoprostol group, but were dose-related. Maternal mortality and manual removal of placenta were not reported in any of the studies $(n=3)$.

\section{Discussion}

The purpose of the review was to assess evidence on the effectiveness of misoprostol compared to a placebo for the prevention and treatment of postpartum haemorrhage. Three trials that fulfilled the inclusion criteria were identified. In meta-analysis of those three trials, there was a non-significant tendency of blood loss of $\geq 500 \mathrm{~mL}$ for participants who received misoprostol (RR 0.65; 95\% CI 0.40-1.06). However, there was a high level of heterogeneity amongst the studies $(p=0.008)$. These findings are not consistent with the metaanalysis performed by Hofmeyer et al. (2005) who found a pooled risk ratio of 0.57 (95\% CI 0.34-0.96). Even though the studies that Hofmeyr et al. (2005) included in their metaanalysis compared misoprostol to a placebo in addition to other uterotonic drugs, the results are of great weight.

There was no incidence of maternal mortalities reported in any of the trials in this review. However, in previous trials by Hofmeyer et al. (2004) there were three maternal deaths out of 117 participants in the misoprostol arm and Widmer et al. (2010) reported two maternal deaths out of 705 participants in the misoprostol arm compared to a placebo. Despite the small number of participants recruited in those two trials, the results should be interpreted with great caution. Only one trial, Derman et al. (2006), reported on the need for a blood transfusion. The study found no significant difference in the need for a blood transfusion between participants who received misoprostol or a placebo (RR 0.14; 95\% CI 0.02-1.15).

As reported in previous trials (Hofmeyr et al. 2004; Hofmeyer et al. 2005; Walraven et al. (2004)) shivering and pyrexia are centrally mediated with prostaglandin use and was significantly more frequent amongst women in the misoprostol group than those in the placebo group. In other clinical trials by Amant et al. (1999) and El-Refaey et al. (1997) the increase in temperature after the administration of misoprostol was a common finding. The findings of increased shivering were comparable with that reported in literature of Hofmeyer et al. (2004), El-Refaey et al. (1997) and Suberk et al. (1999). In the
Hofmeyr et al. (2004) trial, where $1000 \mathrm{mg}$ misoprostol was used, it was stated that the side effects of misoprostol may be related to rapid absorption when given orally and elevated bioavailability when given sublingual. The side effects do not rule out misoprostol for being biologically reasonable to use in the treatment and prevention of $\mathrm{PPH}$ in the absence of conventional uterotonics, as they are dose-related.

There were a total of nine cases of hysterectomy reported in one trial, Derman et al. (2006): one in the misoprostol group and eight in the placebo group (1620 participants; RR 0.12; $95 \%$ CI $0.02-0.99 ; p=0.05)$. Misoprostol has shown a reduced need for additional uterotonics compared to a placebo (RR $0.45 ; 95 \%$ CI $0.21-0.96 ; p=0.04)$. There was no statistical heterogeneity detected amongst the trials $(p=0.84)$.

\section{Practical implications}

Future randomised controlled trials are required to identify the best route and dose of misoprostol for the treatment of primary PPH. Home deliveries in some communities are still evident. It is vital to investigate interventions to control PPH following home deliveries. More importantly, trials must be large enough to assess maternal morbidity and mortality. There has been a lack of research linking the management of the third stage of labour to what has occurred in the first and second stages. It may be timely to assess the possible effects of current strategies for the management of labour on the rates of PPH. None of the included trials has addressed the women's preferences in terms of uterotonic options. It would be of interest to embrace this aspect of care in future research on trials of uterotonic choice.

\section{Overall completeness and applicability of evidence}

This review aimed to discover if misoprostol is more effective than a placebo in the prevention and treatment of $\mathrm{PPH}$. All relevant literature was retrieved. The included studies concentrated on how effective misoprostol is and the body of evidence applies to the research question. All main outcomes of interest were presented in the trials, but not all of the sub-outcomes.

\section{Quality of evidence}

According to Higgins and Green (2006), randomised controlled trials are measured gold standard study designs to answer a problem on the effectiveness of a particular treatment. Therefore trials were restricted to this study 
design. The risk of bias was assessed in three of the included trials. About $75 \%$ of the trials were free from attrition bias, detection bias, performances and reporting bias. About $50 \%$ of the trials were free from selection bias. Only trials that compared misoprostol to a placebo were considered for this review. In all of the trials the treatment was given immediately after the delivery of the interior shoulder of the baby. Even though the estimation of blood loss is known to be difficult and inaccurate, the measurement of blood loss was similar in all trials. Errors in blood measurements are likely to be distributed equally and unlikely to have introduced any systematic bias that could have affected the significance of the study results. Consistency across trials is determined by whether heterogeneity is present or not. During the analysis of the outcomes, two out of eight outcomes showed evidence of heterogeneity. To incorporate heterogeneity amongst studies, random effects meta-analysis was performed.

\section{Potential biases in the review process}

The objective and rationale of the review protocol was modified after careful study of previous trials carried out on the use of misoprostol in obstetrics. Although an extensive literature search was performed, only studies conducted in English were considered for the review. Some trials with imperative information may have been excluded due to the language barrier or because it had to be purchased. Two reviewers judged the relevance of each trial independently using a standardised data extraction form before the trials were included in the review to minimize bias. The Cochrane Collaboration methodological assessment tool was engaged in the assessment of the methodological quality of trials. There was no conflict of interest to be declared by the reviewers.

\section{Agreements and disagreements with other study reviewers}

To our knowledge, this review appears to be the first to perform a meta-analysis on studies that compared misoprostol to a placebo without the use of additional uterotonics. There is a need to carry out more randomised controlled trials on the subject.

\section{Limitations of the study}

The review focused mainly on studies comparing misoprostol to a placebo not in addition to other uterotonics; hence only three trials were included for analysis. This may result in other studies being excluded, which could have influenced the findings of this review. One study (Prata et al. 2005), that was initially included, was excluded after the methodological quality assessment. We only considered studies written in English. With adequate funding we would have conducted a search for studies written in other languages and those identified would have been sent for translation.

\section{Recommendations}

There is a need for large randomised controlled trials to evaluate the effectiveness of the use of misoprostol in the prevention and treatment of $\mathrm{PPH}$. We accentuate that future studies should include using misoprostol alone in interventions - not in addition to other uterotonics, as most studies have been conducted. This could obscure the accurate effect of misoprostol.

\section{Conclusion}

The use of misoprostol was not associated with any significant reduction in the amount of blood loss. Studies included in the review were not large enough to evaluate the effects of misoprostol on maternal mortality in women with primary $\mathrm{PPH}$. Because of the enormous potential impact of PPH on maternal health in poor countries, further research aiming to evaluate the effects of misoprostol on substantive health outcomes, its safety and the optimal route of administration and dosage are of the utmost urgency. Misoprostol is relatively cheap and easy to administer compared with injectable uterotonics (oxytocin and ergometrine), which are considered first-line treatment by WHO. Ergometrine and syntometrine are contraindicated in hypertensive pregnant women as they stimulate vasoconstriction and cause hypertension. Injectable uterotonics require skill, sterile syringes and alcohol swabs to be administered safely, are unstable in tropical conditions and call for special storage facilities to maintain efficacy. Misoprostol is devoid of these constraints and may therefore be an alternative treatment for PPH in developing countries where storage facilities and resources are limited.

\section{Acknowledgements}

We would like to acknowledge the library staff at Stellenbosch University for their assistance in retrieving the articles for this review. We would also like to thank SURMEPI for funding the authors so that they could attend advanced courses in Clinical Trials and systematic reviews and meta-analysis.

\section{Competing interest}

The authors declare that they have no financial or personal relationship(s) that may have inappropriately influenced them in writing this paper.

\section{Author contributions}

K.M.O. (Stellenbosch University) did the review as part fulfillment of her Master's degree in Nursing. O.K. (Stellenbosch University) was the supervisor. K.M.O. conducted the literature search and it was validated by O.K. guided the methodological process from conception to conclusion. K.M.O. wrote the manuscript with the guidance of O.K. and D.M. (Stellenbosch University) was the cosupervisor and assisted in reviewing the systematic review.

\section{References}

Abou-Zahr, C., 2003, 'The global burden of maternal death and disability', British Medical Bulletin 67, 1-11. http://dx.doi.org/10.1093/bmb/ldg015

Amant, F., Spitz, B., Timmerman, D., Corremans, A. \& Van Assche, F.A., 1999, 'Misoprostol compared with methylergometrine for the prevention of postpartum haemorrhage: A double-blind randomized trial', British Journal of Obstetrics and Gynaecology 106, 1066-1070. http://dx.doi.org/10.1111/j.1471-0528.1999. tb08115.x, PMid:10519433

Blum, J., Alfirevic, Z., Walraven, G., Weeks, A. \& Winikoff, B., 2007, 'Treatment of postpartum haemorrhage with misoprostol', International Journal of Gynecology and Obstetrics 99, 202-205. http://dx.doi.org/10.1016/j.ijgo.2007.09.013, PMid:17961565 
Blum, J., Winikoff, B., Raghavan, S., Dabash, R., Ramadan, M.R., Dilbaz, B. et al., 2010, 'Treatment of post-partum haemorrhage with sublingual misoprostol versus oxytocin in women receiving prophylactic oxytocin: a double-blind, randomised oxytocin in women receiving prophylactic oxytocin: a double-blind, randomised, 6736(09)61923-1

Bugalho, A., Daniel, A., Faundes, A. \& Cunha, M., 2001, 'Misoprostol for prevention of postpartum hemorrhage', International Journal of Gynaecology and Obstetrics 73 , 1-6. http://dx.doi.org/10.1016/S0020-7292(01)00346-0

Cook, C.M., Spurrett, B. \& Murray, H., 1999, 'A randomized clinical trial comparing oral misoprostol with synthetic oxytocin or syntometrine in the third stage of labour', Australia and New Zealand Journal of Obstetrics \& Gynaecology 394, 414-419. http://dx.doi.org/10.1111/j.1479-828X.1999.tb03124.x

De Vos, A.S., 2005, 'Qualitative data analysis and interpretation', in A.S. De Vos, H. Strydom, C.B. Foche \& C.S.L. Delport (eds.), Research at grassroots for the social sciences and human service professionals, 3rd edn, pp. 333-349,3rd edn., Pretoria, Van Schaik Publishers.

Deeks, J.J., Higgins, J.P.T. \& Altman, D.G., 2006, 'Analyzing and presenting results', in J.P.T. Higgins, \& S. Green (eds.), Cochrane Handbook for Systematic Reviews of Interventions 4.2.6., pp. 97-166, Chichester, John Wiley \& Sons Ltd.

Derman, R.J., Kodkany, B.S., Goudar, S.S., Geller, S.E., Naik, V.A., Bellad, M.B., et al., 2006, 'Oral misoprostol in preventing postpartum haemorrhage in resource-poo communities: A randomised controlled trial', Lancet 368, 1248-1253. http://dx.do org/10.1016/S0140-6736(06)69522-6

El-Refaey, H., Nooh, R. \& O'Brien, P., 2000, 'The misoprostol third stage of labour study: A randomised controlled comparison between orally administered misoprosto and standard management', British Journal of Obstetrics and Gynaecology 107 1104-1110. http://dx.doi.org/10.1111/j.1471-0528.2000.tb11108.x

El-Refaey, H., O'Brien, P., Morafa, W., Walder, J. \& Rodeck, C., 1997, 'Use of oral misoprostol in the prevention of postpartum haemorrhage', British Journal of Obstetrics and Gynaecology 104, 336-339.

Fawcus, F. \& Moodley, J., 2011, 'Management of postpartum haemorrhage', South African Journal of Obstetrics and Gynaecology 17, 1-3.

Fawole, A.O., Sotiloye, O.S., Hunyinbo, K.I., Umezulike, A.C., Okunlola, M.A. \& Adekanle, D.A., 2010, 'Misoprostol and routine uterotonics for prevention of postpartum hemorrhage: A double-blind, randomized, placebo controlled trial', International Journal of Gynecolology and Obstetrics 112, 107-111. http://dx.doi.org/10.1016/j. ijgo.2010.08.023, PMid:21130446

Gotzsche, P.C., 1989, 'Methodology and overt and hidden bias in reports of 196 double blind trials of non-steroidal anti-inflammatory drugs in rheumatoid arthritis', Controlled Clinical Trials 10, 3-56. http://dx.doi.org/10.1016/0197-2456(89)90017-2

Gülmezoglu, A. M., Fiona, F., Villar, J. \& Hofmeyer, G.J., 2011, Prostaglandins for preventing postpartum Haemorrhage. Cochrane database systematic Review, 3, CD000494.

Gülmezoglu, A.M., Villar, J., Ngoc, N.T., Piaggio, G., Carroli, G., Adetoro, L., et al., 2001, 'WHO collaborative group to evaluate misoprostol in the management of the third stage of labour. WHO multicentre randomised trial of misoprostol in the management of the third stage of labour', Lancet 358, 689-695. PMid:11551574

Higgins, J.P.T. \& Green, S., 2006, Cochrane Handbook for Systematic Reviews of Interventions 4.2.6, Chichester, John Wiley \& Sons Ltd.

Hofmeyr, G.J., Nikodem, V.C., De Jager, M. \& Drakely, A., 2001, 'Side-effects of oral misoprostol in the third stage of labour-A randomised placebo-controlled trial', misoprostol in the third stage of labour-A randomised place
South African Medical Journal 91, 432-435. PMid:11455810

Hofmeyr, G.J., Nikodem, V.C., de Jager, M. \& Gelbart, B.R., 1998, 'A randomised placebo controlled trial of oral misoprostol in the third stage of labour', British Journal of Obstetrics and Gynaecology 105, 971-975. http://dx.doi.org/10.1111/ journal of Obstetrics and Gynaecology 105,

Hofmeyr, G.J., Ferreira, S. \& Nikodem, V.C., 2004, 'Misoprostol for treating postpartum haemorrhage: A randomized controlled trial', BioMedical Centre Pregnancy Childbirth 4, 16. http://dx.doi.org/10.1186/1471-2393-4-16, PMid:15298718, PMCid:514549

Hofmeyr, J.G., Walraven, G., Gülmezoglu, M.A., Maholwana, B., Alfirevic, Z. \& Villar, J., 2005, Misoprostol to treat postpartum haemorrhage: a systematic review, $B J O G$ : an International Journal of Obstetrics and Gynaecology, 112, 547-553.

Hofmeyr, G.J., Walraven, G. \& Gülmezoglu, A.M., 2007, 'Misoprostol to treat postpartum haemorrhage: A systematic review', Journal of Obstetrics and Gynecology 112, 547-553.

Hofmeyr, G.J., Fawole, B., Mugerwa, K., Godi, P., Blignaut, Q., Mangesi, L, et al., 2010, 'Administration of $400 \mu \mathrm{g}$ of misoprostol to augment routine active management of the third stage of labor', International Journal of Gynecology and Obstetric 112, 98-102. http://dx.doi.org/10.1016/j.ijgo.2010.08.019, PMid:21130990

Hoj, L., Cardoso, P., Nielsen, B.B., Hvidman, L., Nielsen, J. \& Aaby, P., 2005, ‘Effect of sublingual misoprostol on severe postpartum haemorrhage in a primary health centre in Guinea-Bissau: A randomised double blind clinical trial', British Medica Journal 331, 723. http://www.unicef.org/infobycountry/southafrica_statistics. html?q=printme, http://dx.doi.org/10.1136/bmj.331.7519.723, PMid:16195287, PMCid:1239973

Langenbach C., 2006, 'Misoprostol in preventing postpartum hemorrhage: A metaanalysis', International Journal of Gynaecology and Obstetrics 92, 10-18. http:// dx.doi.org/10.1016/j.ijgo.2005.10.001, PMid:16309682

Lokugamage, A.U., Sullivan, K.R., Niculescu, O., Tigere, P., Onyangunga, F., El- Refaey, H., et al., 2001, 'A randomized study comparing rectally administered misoprostol versus et al., 2001, A randomized study comparing rectally administered misoprostol versus
syntometrine combined with an oxytocin infusion for the cessation of primary post partum hemorrhage', Acta Obstetrics and Gynecology Scandinavica 80, 835-839. partum hemorrhage', Acta Obstetrics and Gynecology Scandinavica 80, 835-83
http://dx.doi.org/10.1034/j.1600-0412.2001.080009835.x, PMid:11531635

McCormick, M.L., Sanghvi, H.C., Kinzie, B. \& McIntosh, N., 2002, 'Preventing postpartum haemorrhage in low-resource settings', International Journal of Gynecology and Obstetrics 77, 267-275. http://dx.doi.org/10.1016/S0020-7292(02)00020-6
Millennium Development Goals Report (MDGs), 2010, viewed 24 January 2013, from http://www.un.org/millenniumgoals/pdf/MDG\%20Report\%202010\%20En\%20 r15\%20-low\%20res\%2020100615\%20-.pdf

Miller, S., Lester, F. \& Hensleigh, P., 2004, 'Prevention and treatment of postpartum hemorrhage: new advances for low-resource settings', Journal of Midwifery Women's Health 49, 283-292. http://dx.doi.org/10.1016/j.jmwh.2004.04.001, PMid:15236707

Mousa, H.A. \& Alfirevic, Z., 2007, 'Treatment for primary postpartum haemorrhage', Cochrane Database of Systematic Reviews 1, CD003249. PMid:1725348

Ng, P.S., Chan, A.S., Sin, W.K., Tang, L.C., Cheung, K.B. \& Yuen, P.M., 2001, 'A multicentre randomized controlled trial of oral misoprostol and intramuscular syntometrine in the management of the third stage of labour', Human Reproduction 16, 31-35. http://dx.doi.org/10.1093/humrep/16.1.31, PMid:11139532

Pillitteri, A. \& Klweri, W., 2010, Maternal and childbearing nursing: Care of child bearing and child rearing family, Lippincott \& William and Wilton Publishers, New York.

Prendiville, W.J., Elbourne, D. \& McDonald, S, 2000, 'Active versus expectant management in the third stage of labour', Cochrane Database Systematic Review, CD000007.

Prata, N., Mbaruku, G., Campbell, M., Potts, M. \& Vahidnia, F. 2005, Controlling postpartum hemorrhage after home births in Tanzania, International Journal of Gynaecology and Obstetetrics. 90, 51-55. http://dx.doi.org/10.1016/j.ijgo.2005.03.007

Rosenfield, A., Maine, D. \& Freedman, L., 2006, 'Meeting MDG-5: an impossible dream?', Lancet 368, 1133. http://dx.doi.org/10.1016/S0140-6736(06)69386-0

Saving Mothers, 2002-2004, 2006, 'The report on confidential enquiries into maternal deaths in South Africa. Third report', Department of Health, South Africa, 68-95.

Saving Mothers. 2002-2004, 2007, Third Report on Confidential Enquiries into Maternal Deaths in South Africa, Government Printer, Pretoria.

Saving Mothers 2005-2007, 2009, Fourth Report on Confidential Enquiries into Maternal Deaths in South Africa Expanded Executive Summary, National Committe on Confidential Enquiries into Maternal Deaths, Government Printer, Pretoria.

Sellers, P.M, 1995, Midwifery: A textbook and reference book for midwives in South Africa, 2nd edn., South Africa, Creda Press (Pty) Ltd.

Suberk, D.V., Fehr, P.M., Hösli, I. \& Holzgreve, W., 1999, 'Oral misoprostol for third stage of labor: A randomized placebo-controlled trial', Elsevier Science Incorporation 92, 255-258.

Tang, O.S., Schweer, H., Seyberth, H.W., Lee, S.W.H. \& Ho, P.C., 2002, 'Pharmacokinetics of different routes of administration of misoprostol', Human Reproduction 17 332-336. http://dx.doi.org/10.1093/humrep/17.2.332, PMid:11821273

The United Nations Children's Fund (UNICEF), 2008, Countdown to 2015. Maternal, Newborn and Child Survival. Tracking progress in maternal, newborn \& child survival. The 2008 Report, UNICEF, New York.

The United Nations Children's Emergency Funds (UNICEF), 2010, Trends in Maternal Mortality: 1990 to 2008, viewed 10 December 2010, from http://whqlibdoc.who. int/publications/2010/9789241500265_eng.pdf

Tsu, V.D., \& Shane, B., 2004, New and underutilized technologies to reduce maternal mortality: Call to action from a Bellagio workshop, International Journal of Gynaecology and Obstetrics 85, S83-S93. http://dx.doi.org/10.1016/j.ijgo.2004.02.011, PMid:15147857

Villar, J., Gulmezoglu, A.M., Hofmeyer, G.J. \& Forna, F., 2002, 'Systematic Review of randomised controlled trials of misoprostol to prevent Postpartum Haemorrhage', Obstetrics and Gynecology 100, 1301-1312. http://dx.doi.org/10.1016/S0029Obstetrics and Gyne
7844(02)02371-2

Walraven, G., Dampha, Y., Bittaye, B., Sowe, M. \& Hofmeyr, J., 2004, 'Misoprostol in the treatment of postpartum haemorrhage in addition to routine management: A placebo randomized controlled trial', British Journal of Obstetrics and Gynaecology 111 1014-1017. http://dx.doi.org/10.1111/j.1471-0528.2004.00217.x, PMid:15327620

Weeks, A. \& Faúndes, A., 2007, 'Misoprostol in obstetrics and gynecology', International Journal of Gynaecology and Obstetrics 99, 156-159. http://dx.doi.org/10.1016/j. ijgo.2007.09.003, PMid:17961572

Weeks, A., 2006, 'Oral misoprostol for postpartum haemorrhage', Lancet 368, 2123. http://dx.doi.org/10.1016/S0140-6736(06)69856-5

Widmer, M., Blum, J., Hofmeyr, G.J, Carroli, G., Abdel-Aleem, H. \& Lumbiganon, P., 2010, 'Misoprostol as an adjunct to standard uterotonics for treatment of postpartum hemorrhage: A multicentre, double-blind randomized trial', Lance 375(9728), 1808-1813. http://dx.doi.org/10.1016/S0140-6736(10)60348-0

Winikoff, B., Dabash, R., Durocher, J., Darwish, E., Nguyen, T.N. \& León, W., 2010, 'Treatment of post-partum haemorrhage with sublingual misoprostol versus oxytocin in women not exposed to oxytocin during labour: A double-blind, randomised, non-inferiority trial', Lancet 375, 210-216. http://dx.doi.org/10.1016/ S0140-6736(09)61924-3

World Health Organization (WHO), 2000, World Health Report, 2000: Make Every Mother and Child Count, viewed 24 January 2013, from: http://www.who.int/ whr/2000/whr2000_en

World Health Organization, 2007, Maternal Mortality in 2005: Estimates developed by WHO, UNICEF, UNFPA and The World Bank, Geneva, Switzerland.

World Health Organization (WHO), 2007, WHO recommendations for the prevention of postpartum haemorrhage, viewed 18 November 2010, from http://www.who.int/ making pregnancy safer/publications/WHORecommendationsforPPHaemorrhage. pdf

Zuberi, N., Durocher, J., Sikander, R., Baber, N., Blum, J. \& Walraven, G., 2008, 'Misoprostol in addition to routine treatment of postpartum hemorrhage: A hospital-based randomized controlled-trial in Karachi, Pakistan', BioMedical Centre Pregnancy Childbirth 8, 40. http://dx.doi.org/10.1186/1471-2393-8-40, PMid:18718007, PMildbirth 8, 40 . 